\title{
Variabilidade fenotípica de caracteres adaptativos da aveia branca (Avena sativa L.) em cruzamentos dialélicos
}

\author{
Phenotypic variability of adaptive traits in white oat (Avena sativa L.) in diallelic crosses
}

\author{
Irineu Hartwig' José Antônio Gonzalez da SilvaI Fernando Irajá Félix de Carvalho ${ }^{\mathrm{I} *}$ \\ Antonio Costa de Oliveira ${ }^{\mathrm{I}}$ Ivandro Bertan ${ }^{\mathrm{I}}$ Igor Pires Valério \\ Giovani Olegário da SilvaI Guilherme Ribeiro ${ }^{\mathrm{I}}$ \\ Taciane Finatto ${ }^{\mathrm{I}}$ Gustavo da Silveira ${ }^{\mathrm{I}}$
}

\section{RESUMO}

\begin{abstract}
O melhoramento de plantas tem por base a ampliação da variabilidade genética existente através de cruzamentos artificiais planejados. Assim, é de fundamental importância o conhecimento das populações formadas, a fim de prever o potencial das combinações a partir de diferentes genitores, permitindo maior eficiência de seleção para o caráter desejado, otimizando o ganho genético. Dessa forma, o objetivo deste trabalho foi o de observar a variabilidade fenotípica dos caracteres estatura de planta, ciclo vegetativo e ciclo reprodutivo na geração F2 e prever as melhores combinações para a obtenção de constituições genéticas superiores. Para isso, cinco genótipos de aveia (UPF 16, UPF 18, UFRGS 7, UFRGS 17 e URPEL 15) foram cruzados de forma dialélica, sem a realização dos cruzamentos recíprocos, para o desenvolvimento das populações F2. Para analisar a variabilidade nas populações, foram utilizados os parâmetros: média, variância e assimetria da distribuição de freqüência. Os cruzamentos UPF 16 x UFRGS 17 e UFRGS 17 x URPEL 15 produziram grande quantidade de plantas de estatura reduzida. Para o caráter ciclo vegetativo, UPF $16 \times$ UPF 18, UPF $16 \times$ UFRGS 7, UPF $16 \times$ UFRGS 17, UPF $16 \times$ URPEL 15, UFRGS $7 \times$ UFRGS 17 e UFRGS $7 \times$ URPEL 15 foram os cruzamentos que produziram descendentes de ciclo curto. UPF $16 \times$ UFRGS 17 e UPF 16 x URPEL 15 produziram amplo número de progênies de ciclo reprodutivo longo.
\end{abstract}

Palavras-chave: estatura de planta, ciclo vegetativo, ciclo reprodutivo, seleção, população F2, dialelo.

\section{ABSTRACT}

Plant breeding is based on the pursue of an amplification of genetic variability through planned crosses. Thus, it is of fundamental importance to study the formed populations, in order to predict the potential of different parental combinations, allowing a higher selection efficiency for the desired trait, optimizing genetics gains. Thus, the objective of this work was to observe the phenotypic variability of the characters plant stature, vegetative cycle and reproductive cycle in F2 generation and to predict the best combinations to obtain superior genetic constitutions. Therefore, five oat genotypes (UPF 16, UPF 18, UFRGS 7, UFRGS 17 and URPEL 15) were crossed in a diallelic format, without reciprocal crosses, for the development of F2 populations. To analyze population variability, the following parameters were used: mean, variance and asymmetry of frequency distribution. The crosses UPF 16 $x$ UFRGS 17 and UFRGS 17 x URPEL 15 produced a large amount of plants with shorter stature. For the character vegetative cycle, UPF $16 \times$ UPF 18, UPF $16 \times$ UFRGS 7, UPF $16 \times$ UFRGS 17, UPF $16 \times$ URPEL 15, UFRGS $7 \times$ UFRGS 17 and UFRGS $7 \times$ URPEL 15 were the crosses that produced short cycle plants. UPF $16 \times$ UFRGS 17 and UPF $16 \times$ URPEL 15 produced a large number of long-cycled progenies.

Key words: stature of plant, vegetative cycle, reproductive cycle, selection, F2 population, diallel.

\section{INTRODUÇÃO}

A aveia branca (Avena sativa L.) é fonte potencialmente econômica de produção de grãos e de qualidade nutricional para alimentação humana e animal. No Sul do Brasil, constitui uma lavoura alternativa ao trigo para cultivo na estação fria, evidenciando, nos últimos anos, um crescimento acentuado na área cultivada, principalmente pelo aproveitamento dos grãos para comercialização e industrialização e por produzir uma ótima qualidade de palha, que proporciona boa cobertura do solo.

ICentro de Genômica e Fitomelhoramento, Faculdade de Agronomia “Eliseu Maciel” (FAEM), Universidade Federal de Pelotas (UFPel), CP. 354, 96010-900, Pelotas, RS, Brasil. E-mail: carvalho@ufpel.tche.br. *Autor para correspondência. 
Atualmente o melhoramento da aveia está voltado para o desenvolvimento de genótipos com excelente qualidade industrial, rendimento de grãos superior às cultivares existentes no mercado e tolerantes a estresses bióticos e abióticos. Dessa forma, há um grande esforço dos melhoristas em adequar novas constituições genéticas a diferentes interesses e sistemas de cultivo, tendo por base a escolha de genitores-elite para compor os cruzamentos artificiais para possibilitar ganhos mais rapidamente.

A variabilidade genética é de essencial interesse para o melhorista na obtenção de progressos no melhoramento de plantas através da seleção natural ou artificial, viabilizando o emprego de técnicas que possibilitem a identificação de genótipos superiores. Portanto, o estreitamento da base genética entre os genótipos cultivados de aveia branca reduz drasticamente a possibilidade de êxito na seleção artificial para obtenção de diferentes constituições genéticas nas gerações segregantes (CARVALHO \& FEDERIZZI, 1989). Esse fato é de elevada importância, considerando que caracteres adaptativos como estatura e ciclo das plantas são de fácil observação em gerações altamente segregantes, visto que, na maior parte das vezes, são caracteres controlados por um ou por poucos genes de grande efeito no caráter alvo (MITTELMANN et al., 2001).

Como o melhoramento genético de plantas tem por base ampliar a variabilidade existente através de cruzamentos controlados, é de fundamental importância o conhecimento das populações formadas, a fim de prever o potencial das combinações a partir de diferentes genitores, permitindo maior amplitude de seleção para o caráter desejado, otimizando, dessa forma, o ganho genético. Nesse sentido, o objetivo deste trabalho foi observar a variabilidade fenotípica dos caracteres estatura de planta, ciclo vegetativo (dias da emergência à floração) e ciclo reprodutivo (dias da floração à maturação) na geração F2, provenientes de cruzamentos dialélicos, e estimar as melhores combinações para a obtenção de constituições genéticas superiores.

\section{MATERIAL E MÉTODOS}

Cinco genótipos de aveia (UPF 16, UPF 18, UFRGS 7, UFRGS 17 e uma linhagem denominada URPEL 15) foram cruzadas de forma dialélica, sem a realização dos cruzamentos recíprocos, em telado, no ano de 2003. Os genitores foram escolhidos com base no rendimento de grãos e em caracteres agronômicos de interesse, bem como pela dissimilaridade morfológica apresentada pelos genitores. As sementes F2 foram obtidas pela autofecundação das plantas F1. O experimento foi realizado no ano agrícola de 2004 com as populações F2 e os seus respectivos genitores conduzidos em campo experimental no Centro Agropecuário da Palma, pertencente ao Centro de Genômica e Fitomelhoramento - FAEM/UFPel, localizado no município de Capão do Leão/RS. O município está situado a 31 52' 00” de latitude Sul e $52^{\circ} 21^{\prime} 24^{\prime}$ 'de longitude, a uma altitude de $13,24 \mathrm{~m}$, sendo o clima do tipo Cfa, com uma precipitação pluviométrica média anual de 1280,2mm (MORENO, 1961). O solo da área experimental pertence à unidade de mapeamento Pelotas, classificado como Argissolo VermelhoAmarelo distrófico de textura argilosa e relevo ondulado, com presença do lençol freático próximo à superfície (EMBRAPA, 1999).

A área experimental foi preparada convencionalmente e adubada de acordo com análise de solo. Para o controle das plantas invasoras, foi efetuada a aplicação dos produtos designados comercialmente Basagran e Allay, conforme indicações técnicas para a cultura (CBPA, 2003) e capina manual, quando necessário. O delineamento empregado no experimento foi o completamente casualizado, onde cada planta foi considerada uma unidade de observação. Cada parcela foi composta por linhas casualizadas de uma população F2 oriunda de um cruzamento e de linhas dos seus respectivos genitores. As plantas foram cultivadas em linhas de $3 \mathrm{~m}$ de comprimento e espaçadas $0,3 \mathrm{~m}$ entre e dentro da linha. $\mathrm{O}$ número de plantas avaliadas nos genitores e nas populações F2 foi variável de acordo com a disponibilidade de sementes de cada população F2. Os caracteres avaliados foram: número de dias da emergência a floração (ciclo vegetativo), número de dias da floração a maturação (ciclo reprodutivo) e estatura de planta, aferida em cm da base do colmo ao ápice da panícula principal.

As estimativas dos parâmetros avaliados foram obtidas através dos procedimentos PROC GLM e TTEST do pacote estatístico SAS (SCHLOTZHAUER \& LITTELL, 1987), de modo a estimar a média, a variância e a assimetria das populações e dos genitores empregados no estudo.

\section{RESULTADOSE DISCUSSÃO}

Podem ser observadas diferenças significativas quanto às estatísticas de médias e variâncias para o caráter estatura de planta (Tabela 1), ciclo vegetativo (Tabela 2 ) e ciclo reprodutivo (Tabela 3) nas gerações F2, em relação aos genitores em grande parte dos cruzamentos estudados. Entre as populações avaliadas, as progênies do cruzamento UPF 16 x UFRGS 
Tabela 1 - Assimetria (a), média populacional $(\mu)$, variância $\left(\sigma^{2}\right)$ e número de plantas avaliadas (n) para o caráter estatura de plantas (cm) dos genitores e da geração segregante $F_{2}$ oriunda dos cruzamentos artificiais entre cinco genótipos UPF 16, UPF 18, UFRGS 7, UFRGS 17 e URPEL 15. Pelotas, RS, 2005.

\begin{tabular}{|c|c|c|c|c|c|}
\hline Populações & Geração & $\mathrm{n}$ & $\mu$ & $\sigma^{2}$ & $\mathrm{a}$ \\
\hline UPF 16 & Testemunha & 31 & 108 & 17,31 & $-0,42$ \\
\hline UPF 18 & Testemunha & 37 & 111 & 35,29 & $-0,92$ \\
\hline UPF 16 x UPF 18 & $\mathrm{~F}_{2}$ & 224 & 110 & 61,95 & $-0,14$ \\
\hline UPF 16 & Testemunha & 26 & 101 & 30,65 & 0,14 \\
\hline UFRGS 7 & Testemunha & 43 & 81 & 16,14 & $-0,40$ \\
\hline UPF 16 x UFRGS 7 & $\mathrm{~F}_{2}$ & 208 & $90 *$ & 52,77 & 0,41 \\
\hline UPF 16 & Testemunha & 23 & 95 & 26,09 & $-0,09$ \\
\hline UFRGS 17 & Testemunha & 42 & 95 & 45,71 & 0,54 \\
\hline UPF 16 x UFRGS 17 & $\mathrm{~F}_{2}$ & 226 & $88 *$ & $130,16^{*}$ & $-0,04$ \\
\hline UPF 16 & Testemunha & 25 & 88 & 97,92 & $-0,97$ \\
\hline URPEL 15 & Testemunha & 33 & 78 & 23,58 & $-1,12$ \\
\hline UPF 16 x URPEL 15 & $\mathrm{~F}_{2}$ & 210 & 84 & 80,82 & 0,21 \\
\hline UPF 18 & Testemunha & 37 & 101 & 50,19 & $-2,20$ \\
\hline UFRGS 7 & Testemunha & 39 & 78 & 25,94 & $-0,34$ \\
\hline UPF 18 x UFRGS 7 & $\mathrm{~F}_{2}$ & 222 & 101 & 106,23 & $-0,45$ \\
\hline UPF 18 & Testemunha & 37 & 108 & 39,75 & $-0,65$ \\
\hline UFRGS 17 & Testemunha & 41 & 99 & 71,52 & $-0,07$ \\
\hline UPF 18 x UFRGS 17 & $\mathrm{~F}_{2}$ & 86 & 97 & 68,67 & 0,40 \\
\hline UPF 18 & Testemunha & 40 & 104 & 45,58 & $-0,04$ \\
\hline URPEL 15 & Testemunha & 35 & 85 & 28,49 & 0,44 \\
\hline UPF 18 x URPEL 15 & $\mathrm{~F}_{2}$ & 230 & $99 *$ & 68,87 & $-0,61$ \\
\hline UFRGS 7 & Testemunha & 43 & 81 & 32,46 & $-0,05$ \\
\hline UFRGS 17 & Testemunha & 42 & 102 & 45,06 & $-0,11$ \\
\hline UFRGS 7 x UFRGS 17 & $\mathrm{~F}_{2}$ & 223 & $92 *$ & 86,32 & $-0,11$ \\
\hline UFRGS 7 & Testemunha & 37 & 80 & 19,97 & $-0,08$ \\
\hline URPEL 15 & Testemunha & 37 & 88 & 30,86 & $-1,04$ \\
\hline UFRGS 7 x URPEL 15 & $\mathrm{~F}_{2}$ & 213 & $97 *$ & $88,36^{*}$ & 0,22 \\
\hline UFRGS 17 & Testemunha & 41 & 94 & 52,23 & 0,24 \\
\hline URPEL 15 & Testemunha & 35 & 86 & 19,32 & 0,26 \\
\hline UFRGS 17 x URPEL 15 & $\mathrm{~F}_{2}$ & 87 & 85 & $198,96 *$ & $-0,18$ \\
\hline
\end{tabular}

*significativo a 5\% de probabilidade pelo teste t para as médias e pelo F para variâncias em relação à testemunha.

17 revelaram intensa variabilidade para seleção de indivíduos de diferentes estaturas por ter indicado média distinta e variância elevada e significativa na geração F2 em relação aos genitores (Tabela 1). Fato que permite estabelecer a hipótese da existência de genes distintos nos genitores (genes complementares), visto que os genótipos fixos revelaram estaturas similares e a população F2 expressou segregação transgressiva. Quando a variância é modificada na população segregante, pode ser aceita a hipótese de mais de um gene controlando o caráter por determinar maior número de classes de estatura de planta na geração F2 em relação aos pais (GREGORY, 1967).

O melhorista de plantas, além de conhecer os parâmetros da população sob estudo, deve entender o controle genético e a variabilidade genética disponível para o caráter. Sendo assim, em muitas análises genéticas, o objetivo maior é caracterizar a posição e a variabilidade de uma série de dados obtidos a campo; portanto, uma caracterização mais eficiente dos dados pode ser realizada pelos parâmetros genéticoestatísticos de assimetria e curtose (COIMBRA et al., 2005). Uma distribuição ou série de dados é simétrica $(\mathrm{a}=0)$ se observado o mesmo desvio tanto para um lado, quanto para o lado da curva de distribuição. As distribuições F2 são simétricas quando não há ação gênica de dominância por gene(s) envolvidos no caráter (ALLARD, 1960). O valor reduzido e negativo de assimetria $(\mathrm{a}=-0,04)$ apresentado pelo cruzamento UPF 16 x UFRGS 17 para o caráter estatura de plantas indica que quase não há afastamento das observações individuais em relação ao ponto de referência, que é a média da população F2, provavelmente pela ausência de dominância e pela intensa participação de 
Tabela 2 - Assimetria (a), média populacional $(\mu)$, variância $\left(\sigma^{2}\right)$ e número de plantas avaliadas (n) para o caráter ciclo vegetativo (dias) dos genitores e da geração segregante $F_{2}$ oriunda dos cruzamentos artificiais entre cinco genótipos UPF 16, UPF 18, UFRGS 7 , UFRGS 17 e URPEL 15. Pelotas, RS, 2005.

\begin{tabular}{|c|c|c|c|c|c|}
\hline Populações & Geração & $\mathrm{n}$ & $\mu$ & $\sigma^{2}$ & $\mathrm{a}$ \\
\hline UPF 16 & Testemunha & 31 & 100 & 4,45 & 0,11 \\
\hline UPF 18 & Testemunha & 37 & 106 & 1,33 & 0,23 \\
\hline UPF 16 x UPF 18 & $\mathrm{~F}_{2}$ & 224 & 102 & $36,72 *$ & $-0,40$ \\
\hline UPF 16 & Testemunha & 26 & 101 & 3,05 & 0,58 \\
\hline UFRGS 7 & Testemunha & 43 & 101 & 2,58 & $-0,83$ \\
\hline UPF 16 x UFRGS 7 & $\mathrm{~F}_{2}$ & 208 & 99 & $30,13^{*}$ & $-0,31$ \\
\hline UPF 16 & Testemunha & 23 & 103 & 3,13 & 0,08 \\
\hline UFRGS 17 & Testemunha & 42 & 98 & 3,82 & $-0,87$ \\
\hline UPF 16 x UFRGS 17 & $\mathrm{~F}_{2}$ & 226 & 98 & $40,42 *$ & $-0,15$ \\
\hline UPF 16 & Testemunha & 25 & 103 & 5,17 & 0,79 \\
\hline URPEL 15 & Testemunha & 33 & 96 & 4,67 & $-0,82$ \\
\hline UPF 16 x URPEL 15 & $\mathrm{~F}_{2}$ & 210 & 97 & $29,64 *$ & $-0,58$ \\
\hline UPF 18 & Testemunha & 37 & 105 & 3,47 & $-0,45$ \\
\hline UFRGS 7 & Testemunha & 39 & 101 & 2,02 & $-0,20$ \\
\hline UPF 18 x UFRGS 7 & $\mathrm{~F}_{2}$ & 222 & 105 & $24,40 *$ & $-0,49$ \\
\hline UPF 18 & Testemunha & 37 & 105 & 2,41 & $-0,19$ \\
\hline UFRGS 17 & Testemunha & 41 & 97 & 4,16 & $-0,50$ \\
\hline UPF 18 x UFRGS 17 & $\mathrm{~F}_{2}$ & 86 & 102 & $20,62 *$ & $-0,33$ \\
\hline UPF 18 & Testemunha & 40 & 107 & 2,30 & $-0,20$ \\
\hline URPEL 15 & Testemunha & 35 & 95 & 2,12 & $-0,15$ \\
\hline UPF 18 x URPEL 15 & $\mathrm{~F}_{2}$ & 230 & $101^{*}$ & $13,80 *$ & $-0,27$ \\
\hline UFRGS 7 & Testemunha & 43 & 99 & 2,11 & 0,44 \\
\hline UFRGS 17 & Testemunha & 42 & 96 & 3,58 & $-1,07$ \\
\hline UFRGS 7 x UFRGS 17 & $\mathrm{~F}_{2}$ & 223 & 98 & $36,10^{*}$ & $-0,30$ \\
\hline UFRGS 7 & Testemunha & 37 & 101 & 2,64 & $-0,05$ \\
\hline URPEL 15 & Testemunha & 37 & 95 & 3,64 & 0,52 \\
\hline UFRGS 7 x URPEL 15 & $\mathrm{~F}_{2}$ & 213 & 96 & $37,54^{*}$ & $-0,19$ \\
\hline UFRGS 17 & Testemunha & 41 & 99 & 3,26 & 0,38 \\
\hline URPEL 15 & Testemunha & 35 & 95 & 3,95 & 0,11 \\
\hline UFRGS 17 x URPEL 15 & $\mathrm{~F}_{2}$ & 87 & 100 & $25,31 *$ & $-0,33$ \\
\hline
\end{tabular}

*significativo a 5\% de probabilidade pelo teste t para as médias e pelo F para variâncias em relação à testemunha.

aditividade. Além disso, evidenciou-se elevada amplitude (formação de muitas classes), com valores aproximados de 55 a $125 \mathrm{~cm}$ de estatura de planta (Figura 1), o que pode possibilitar ao melhorista sucesso na seleção no caráter.

Nos cruzamentos UPF $16 x$ UPF 18, UPF $16 x$ URPEL 15, UPF 18 x UFRGS 7 e UPF 18 x UFRGS 17 (Tabela 1), os resultados de médias e variâncias permitem afirmar que não há diferenças genéticas entre os genitores incluídos para o caráter estatura de plantas. Assim, as variâncias obtidas e as diferenças de estatura em comparação aos genitores dos cruzamentos provavelmente tenham sido determinadas pelos efeitos de ambiente. Por outro lado, nos cruzamentos UPF 16 x UFRGS 7, UPF 18 x URPEL 15 e UFRGS 7 x UFRGS 17, as alterações observadas foram somente na média, não evidenciando valores significativos da variância da F2 em relação aos genitores. Esse fato permite estabelecer a hipótese de que as diferenças entre os genitores envolvidos nesses cruzamentos artificiais são de apenas um gene de grande efeito no caráter (GREGORY, 1967). Já no cruzamento UFRGS 17 x URPEL 15, pela elevada amplitude da variância, pode ser levantada a hipótese do envolvimento de um grande número de genes com pequeno efeito na expressão do caráter. Contudo, na analise do cruzamento UFRGS 7 x URPEL 15, tambémé verificado que a média e a variância apresentam diferenças significativas em relação à testemunha, permitindo demonstrar que a média da população F2 superou os genitores, com aumento da estatura. Porém, constatou-se grande número de classes formadas (Figura 1), provavelmente pela ação de vários genes de efeito aditivo envolvidos no controle do caráter. 
Tabela 3 - Assimetria (a), média populacional $(\mu)$, variância $\left(\sigma^{2}\right)$ e número de plantas avaliadas (n) para o caráter ciclo reprodutivo (dias) dos genitores e da geração segregante $F_{2}$, oriunda dos cruzamentos artificiais entre cinco genótipos UPF 16, UPF 18, UFRGS 7 , UFRGS 17 e URPEL 15. Pelotas, RS, 2005.

\begin{tabular}{|c|c|c|c|c|c|}
\hline Populações & Geração & $\mathrm{n}$ & $\mu$ & $\sigma^{2}$ & $\mathrm{a}$ \\
\hline UPF 16 & Testemunha & 31 & 40 & 4,45 & $-0,11$ \\
\hline UPF 18 & Testemunha & 37 & 34 & 1,33 & $-0,23$ \\
\hline UPF 16 x UPF 18 & $\mathrm{~F}_{2}$ & 224 & 35 & $24,80^{*}$ & 0,75 \\
\hline UPF 16 & Testemunha & 26 & 38 & 2,98 & $-0,49$ \\
\hline UFRGS 7 & Testemunha & 43 & 34 & 2,74 & 1,19 \\
\hline UPF 16 x UFRGS 7 & $\mathrm{~F}_{2}$ & 208 & 37 & $24,34 *$ & 0,59 \\
\hline UPF 16 & Testemunha & 23 & 37 & 4,08 & $-0,29$ \\
\hline UFRGS 17 & Testemunha & 42 & 37 & 3,83 & 0,88 \\
\hline UPF 16 x UFRGS 17 & $\mathrm{~F}_{2}$ & 226 & $40 *$ & $35,92 *$ & 0,22 \\
\hline UPF 16 & Testemunha & 25 & 37 & 5,17 & $-0,79$ \\
\hline URPEL 15 & Testemunha & 33 & 40 & 7,82 & 0,24 \\
\hline UPF 16 x URPEL 15 & $\mathrm{~F}_{2}$ & 210 & 40 & $26,84^{*}$ & 0,53 \\
\hline UPF 18 & Testemunha & 37 & 35 & 3,47 & 0,45 \\
\hline UFRGS 7 & Testemunha & 39 & 33 & 13,83 & 0,89 \\
\hline UPF 18 x UFRGS 7 & $\mathrm{~F}_{2}$ & 222 & 33 & 22,35 & $-0,18$ \\
\hline UPF 18 & Testemunha & 37 & 35 & 2,28 & 0,17 \\
\hline UFRGS 17 & Testemunha & 41 & 35 & 4,15 & 0,50 \\
\hline UPF 18 x UFRGS 17 & $\mathrm{~F}_{2}$ & 86 & 37 & $19,07 *$ & $-0,06$ \\
\hline UPF 18 & Testemunha & 40 & 33 & 2,30 & 0,20 \\
\hline URPEL 15 & Testemunha & 35 & 39 & 11,44 & 1,09 \\
\hline UPF 18 x URPEL 15 & $\mathrm{~F}_{2}$ & 230 & $36 *$ & 18,03 & 0,21 \\
\hline UFRGS 7 & Testemunha & 43 & 33 & 2,11 & $-0,44$ \\
\hline UFRGS 17 & Testemunha & 42 & 39 & 12,71 & 0,26 \\
\hline UFRGS 7 x UFRGS 17 & $F_{2}$ & 223 & 38 & 30,37 & 0,10 \\
\hline UFRGS 7 & Testemunha & 37 & 33 & 28,31 & 0,23 \\
\hline URPEL 15 & Testemunha & 37 & 42 & 17,94 & $-0,34$ \\
\hline UFRGS 7 x URPEL 15 & $\mathrm{~F}_{2}$ & 213 & $39 *$ & 31,27 & 0,19 \\
\hline UFRGS 17 & Testemunha & 41 & 36 & 17,95 & 0,68 \\
\hline URPEL 15 & Testemunha & 35 & 42 & 18,14 & $-0,33$ \\
\hline UFRGS 17 x URPEL 15 & $\mathrm{~F}_{2}$ & 87 & 40 & 26,07 & 0,33 \\
\hline
\end{tabular}

*significativo a 5\% de probabilidade pelo teste t para as médias e pelo $\mathrm{F}$ para variâncias em relação à testemunha.

Um fato que deve ser levado em consideração para a seleção, no sentido de obter constituições genéticas de estatura reduzida, é a correlação de caracteres adaptativos em cada população formada com os demais caracteres. Correlações positivas entre estatura de planta e número de panículas por planta foram verificados em dois cruzamentos de aveia, indicando que a seleção de plantas de estatura reduzida não necessariamente garante elevado número de afilhos, sendo justamente o caráter número de afilhos altamente correlacionado com o rendimento de grãos em planta individual (BENIN et al., 2003). Por outro lado, é possível que mesmo as plantas sendo menos produtivas quando conduzidas individualmente (sem competição), estas sejam constituições genéticas promissoras quando em lavouras comerciais, por permitirem maior densidade de semeadura e maior quantidade de adubo, sem implicações no acamamento, fator que provoca grandes perdas no rendimento de grãos e na qualidade de grãos de aveia.

A redução no ciclo da cultura de aveia branca tem sido buscada pelos programas de melhoramento, principalmente por permitir que as lavouras de estação fria completem o seu ciclo de cultivo até o período preferencial de instalação da cultura subseqüente (estação quente), que, muitas vezes, é a de maior retorno econômico para o produtor. Porém, apenas o ciclo vegetativo ou reprodutivo em aveia dificilmente é visto como critério de seleção. Isso provavelmente seja devido à maior facilidade de avaliação do ciclo total da planta, pois é provável que, em aveia, possa existir um efeito compensatório entre ciclo vegetativo e ciclo reprodutivo, relacionado ao 


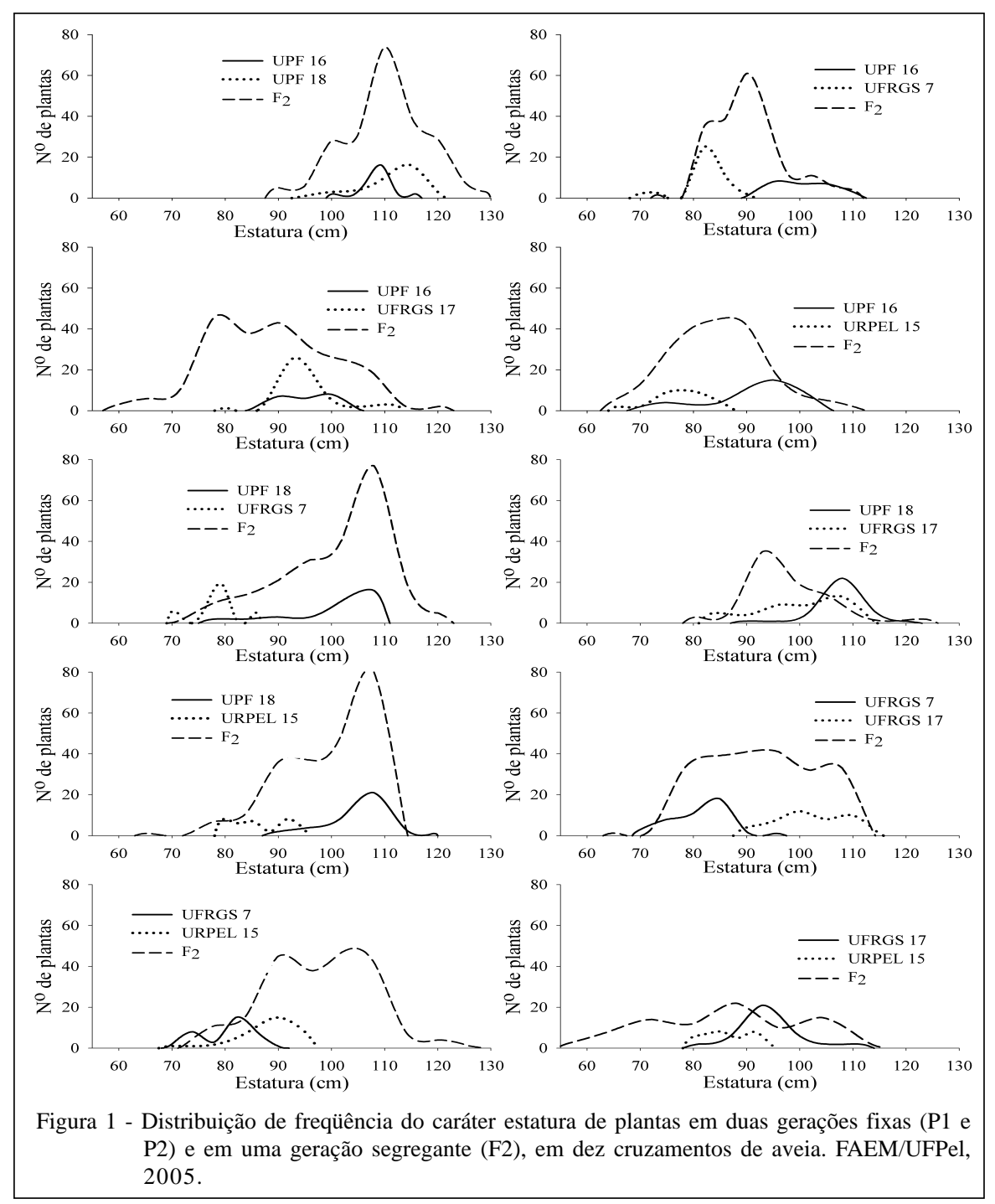

ciclo total da planta, ou seja, quando o genótipo reduz o período vegetativo, tende a prolongar o período reprodutivo e/ou efeito inverso.

No caráter ciclo vegetativo, houve diferença significativa na variância em todas as populações provenientes dos cruzamentos artificiais realizados (Tabela 2), demonstrando a possibilidade de um grande número de genes de pequeno efeito responsável pela manifestação do caráter; fato este que poderá acarretar em dificuldades de seleção, pela maior participação do efeito de ambiente. Esta considerável amplitude de variabilidade observada na geração F2, em relação aos genitores, representa importante informação, pois, ao contrário das mutações (indutores de variabilidade), que causam principalmente mudanças na estrutura gênica, resultando em variabilidade, a hibridação artificial combina genes favoráveis provenientes de diferentes genitores, porém, quando geneticamente muito próximos, as progênies podem determinar uma reduzida variabilidade, o que não foi evidenciado.

Analisando o cruzamento UPF 18 x URPEL 15 (Tabela 2), este representou a única combinação que além das diferenças entre a variância da população F2 em relação aos genitores, também apresentou diferenças entre as médias, implicando a possibilidade de mais de um gene na ação do caráter, e com grande participação da aditividade, visto que a média da população F2 representa o valor médio entre os genitores do cruzamento. Contudo, todos os cruzamentos artificiais realizados foram efetivos na alteração da magnitude da variância quanto ao caráter ciclo vegetativo e apresentaram assimetria negativa. Isso evidencia a tendência da ação gênica de dominância no sentido de aumentar o caráter, pois as 
estimativas desse parâmetro indicam uma tendência dos indivíduos em relação à média. $\mathrm{O}$ ciclo reprodutivo está positivamente correlacionado com o rendimento de grãos e o peso do hectolitro (BENIN et al., 2003). Isso poderia ser justificado, uma vez que essas plantas teriam maior período para o enchimento de grãos e, conseqüentemente, aumento no peso médio de grão, ao contrário da seleção para elevar o período vegetativo. Também uma associação negativa do caráter rendimento de grãos com ciclo vegetativo foi observada por LORENCETTI (2004), permitindo inferir que a seleção para obter plantas com menor número de dias da emergência à floração e maior período da floração à maturação poderá proporcionar a seleção de genótipos mais produtivos. Contudo, as estimativas de correlações são dependentes da constituição genética avaliada e do ambiente sob estudo, pois as associações entre caracteres podem ser atribuídas a efeitos modificadores do ambiente e a diferentes mecanismos fisiológicos, controlando independentemente a expressão do caráter para cada população analisada (FALCONER, 1987).

O balanceamento entre o ciclo vegetativo e o reprodutivo é fundamental. Dessa forma, é essencial o desenvolvimento completo das estruturas vegetativas e a acumulação de fotoassimilados, para que, na fase reprodutiva, ocorra rápida e suficiente translocação destes produtos para promover o completo enchimento de grãos. Observando a figura 2, é possível identificar vários cruzamentos (UPF 16 x UPF 18, UPF 16 x UFRGS 7, UPF $16 x$ UFRGS 17, UPF $16 x$ URPEL 15, UFRGS $7 x$ UFRGS 17 e UFRGS 7 x URPEL 15) que possibilitam a seleção de plantas precoces, além de terem revelado ampla variabilidade (Tabela 2), podendo ser considerados cruzamentos potencias na seleção para tal caráter.

No caráter ciclo reprodutivo, ficou constatado que o cruzamento UPF 16 x UFRGS 17

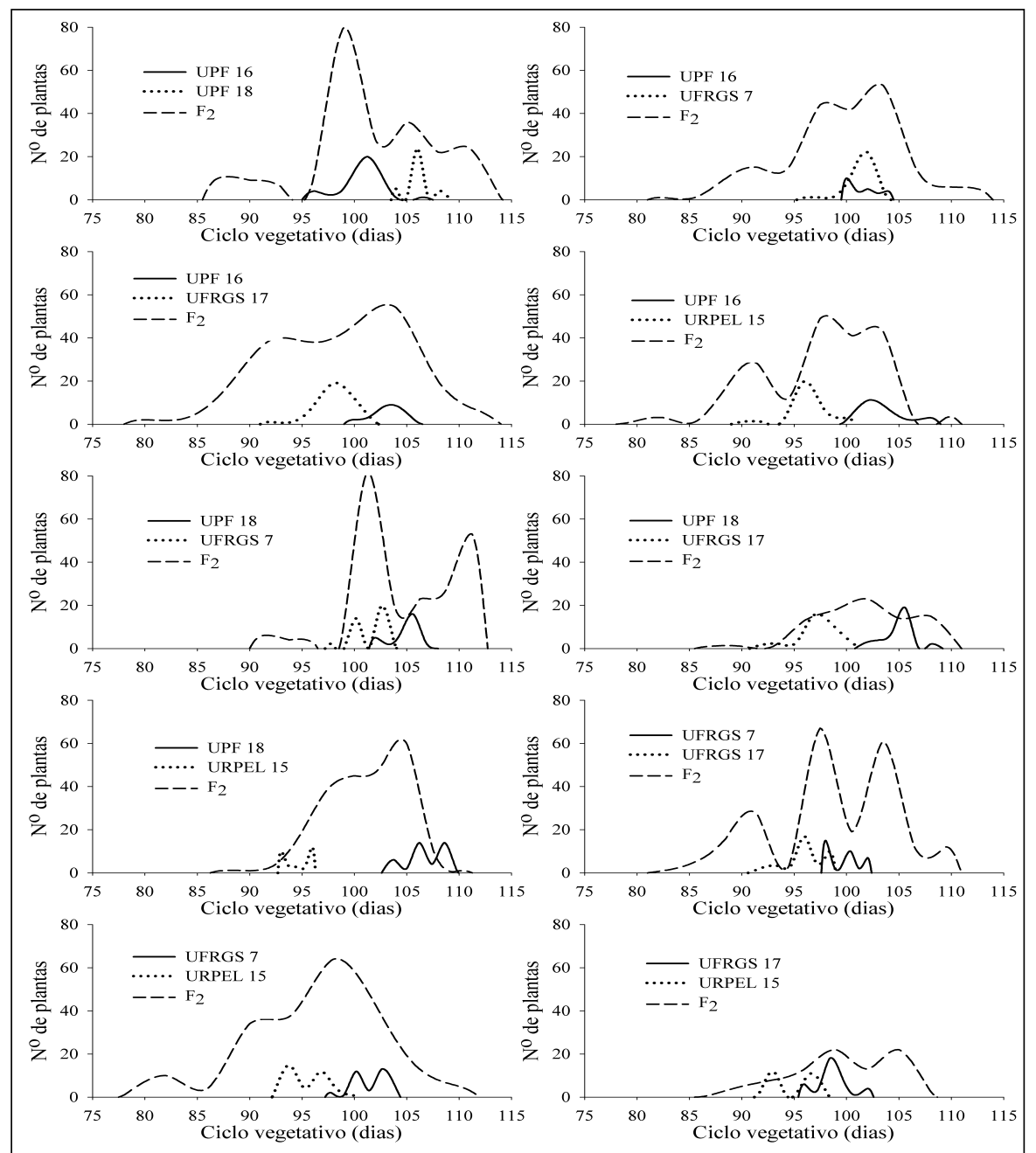

Figura 2 - Distribuição de freqüência do caráter ciclo vegetativo em duas gerações fixas (P1 e P2) e em uma geração segregante (F2), em dez cruzamentos de aveia. FAEM/UFPel, 2005.

Ciência Rural, v.37, n.2, mar-abr, 2007. 
apresentou diferenças quanto aos parâmetros de média e variância da geração F2, em relação aos genitores (Tabela 3), demonstrando variabilidade para ciclo reprodutivo. Além disso, é possível inferir sobre a hipótese de genes distintos existentes nos genitores pela expressão de complementaridade observada na população segregante (segregação transgressiva), com aumento de dias do florescimento à maturação da população F2. Adicionalmente, foi verificada uma amplitude de 25 a 57 dias da floração à maturação (Figura 3), permitindo ao melhorista atuar na seleção de plantas no sentido de elevar ou reduzir o caráter pela seleção. Por outro lado, nos cruzamentos envolvendo as combinações UPF 18 x UFRGS 7, UFRGS 7 x UFRGS 17 e UFRGS 17 x URPEL 15, as médias e variâncias da população F2 não diferiram dos genitores, indicando que não há diferenças genéticas entre os genitores para o caráter ciclo reprodutivo, no qual as diferenças apresentadas, bem como o deslocamento da distribuição da geração F2 pelos valores de assimetria apresentados, tenham sido determinados pela maior participação dos efeitos de ambiente.

Nos cruzamentos envolvendo UPF 16 x UPF 18, UPF 16 x UFRGS 7, UPF 16 x URPEL 15 e UPF $18 x$ UFRGS 17, apenas o parâmetro variância apresentou significância na comparação da geração F2 em relação aos genitores, evidenciando com isso a hipótese da manifestação de um maior número de genes de pequeno efeito sobre o caráter. Além disso, os valores elevados de assimetria positiva indicaram um grande número de indivíduos com dias da emergência à maturação menores que a média da população F2, exceto no cruzamento UPF 18 x UFRGS 17, que se mostrou quase simétrica $(a=-0,06)$, determinando, com isso, grande efeito de aditividade desta combinação. Contudo, amplitudes para seleção de indivíduos foram observadas, apresentando como destaque para incremento de dias da floração à maturação os
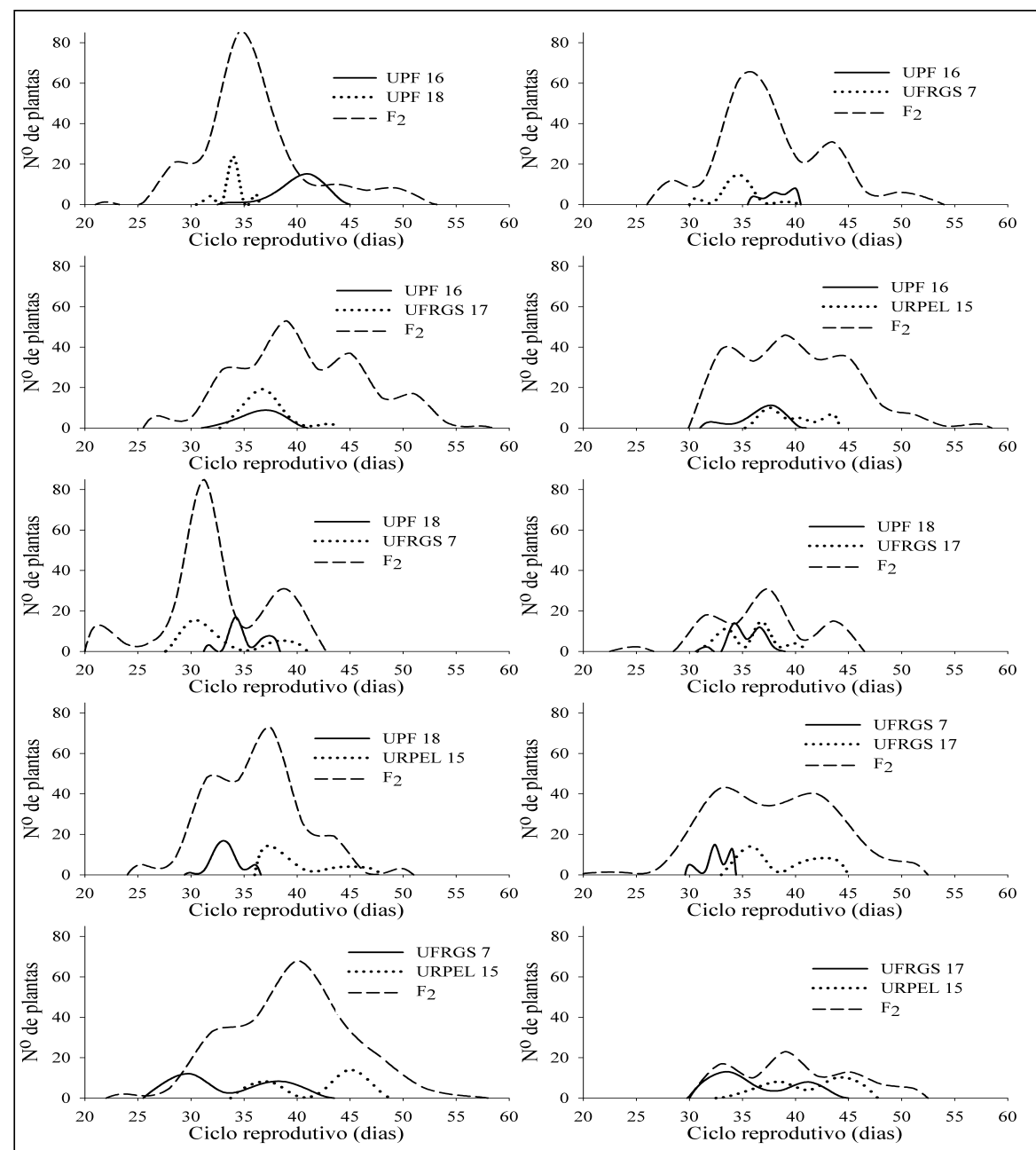

Figura 3 - Distribuição de freqüência do caráter ciclo reprodutivo em duas gerações fixas (P1 e P2) e em uma geração segregante (F2), em dez cruzamentos de aveia. FAEM/UFPel, 2005.

Ciência Rural, v.37, n.2, mar-abr, 2007. 
cruzamentos UPF 16x UFRGS 17 e UPF 16 x URPEL 15, determinando um intervalo aproximado de 25 a 58 dias e de 30 a 58 dias, respectivamente. Já nos cruzamentos entre UPF 18 x URPEL 15 e UFRGS 7 x URPEL 15, diferenças foram observadas somente na média da população F2 em relação aos genitores, indicando provavelmente a ação de apenas um gene de grande efeito controlando o caráter.

Com base nos resultados deste trabalho, foi possível observar que as constituições genéticas UPF 16, UFRGS 17 e URPEL 15 expressaram grande número de progênies de baixa estatura em populações segregantes provenientes dos cruzamentos artificiais entre elas, por possuírem genes para redução da estatura. Além disso, o genótipo UPF 16 revelou descendentes de ciclo vegetativo curto nas populações segregantes oriundas das hibridações realizadas com outros genótipos de aveia, assim como UFRGS 7, quando combinado com UFRGS 17 e URPEL 15. Também o genótipo UPF 16 cruzado com UFRGS 17 e URPEL 15 produziram amplo número de progênies de ciclo reprodutivo longo.

\section{REFERÊNCIAS}

ALLARD, R.W. Principle of plant breeding. 3.ed. New York: J. Wiley, 1960. 485p.

BENIN, G. et al. Estimativas de correlações e coeficientes de trilha como critério de seleção para rendimento de grãos em aveia. Revista Brasileira de Agrociência, Pelotas, v.9, n.1, p.09-16, 2003.
CARVALHO, F.I.F.; FEDERIZZI, L.C. Evolução da cultura da aveia no sul do Brasil. Trigo e Soja, Porto Alegre, v.102, p.1619, 1989.

COIMBRA, J.L.M. et al. Comparação entre mutagênicos químico e físico em populações de aveia. Pesquisa Agropecuária Brasileira, Brasília, v.35, n.1, p.46-55, 2005.

COMISSÃO BRASILEIRA DE PESQUISA DE AVEIA. Indicações técnicas para cultura da aveia. Passo Fundo: UPF, 2003. 87p.

EMBRAPA. Sistema brasileiro de classificação de solos. Brasília, 1999. 412p.

FALCONER, D.S. Introdução à genética quantitativa. Viçosa: UFV, 1987. 297p.

GREGORY, W.C. Mutation breeding. In: FREY, K.J. Plant breeding. Ames: Iowa State University, 1967. Cap.5, p.189217.

LORENCETTI, C. Capacidade combinatória de genitores e suas implicações no desenvolvimento de progênies superiores em aveia (Avena sativa L.). 2004. 93f. Tese (Doutorado em Agronomia) - Curso de Pós-graduação em Agronomia, Universidade Federal de Pelotas.

MITTELMANN, A. et al. Herdabilidade para os caracteres ciclo vegetativo e estatura de planta em aveia. Ciência Rural, Santa Maria, v.31, n.6, p.999-1002, 2001.

MORENO, J.A. Clima do Rio Grande do Sul. Porto Alegre: Secretaria da Agricultura - RS, 1961. 41p.

SCHLOTZAUER, S.D.; LITTELL, R.C. SAS system for elementary statistical analysis. Cary, 1987. 399p. 